\title{
Estudo da obtenção do Regime Permanente de Desgaste em ensaios de desgaste micro-abrasivo por esfera rotativa conduzidos em corpos-de-prova de WC-Co P20 e aço-ferramenta M2
}

\author{
Study of the Steady-State of Wear in micro-abrasive \\ wear tests by rotative ball conducted on specimen \\ of WC-Co P20 and M2 tool-steel
}

\begin{abstract}
Ronaldo Câmara Cozza ${ }^{1,2}$
${ }^{1}$ Centro Universitário FEI - Fundação Educacional Inaciana "Padre Sabóia de Medeiros" - Departamento de Engenharia Mecânica - Av. Humberto de Alencar Castelo Branco, 3972 - 09850-901 - São Bernardo do Campo - SP

${ }^{2}$ CEETEPS - Centro Estadual de Educação Tecnológica "Paula Souza" - FATEC-Mauá - Departamento de Fabricação Mecânica - Av. Antônia Rosa Fioravante, 804 - 09390-120 - Mauá - SP

e-mails: rcamara@fei.edu.br; ronaldo.cozza@fatec.sp.gov.br
\end{abstract}

\section{RESUMO}

Desde a sua inserção junto à comunidade científica de tribologistas, o ensaio de desgaste micro-abrasivo por esfera rotativa vem sendo adotado por renomadas universidades e centros de pesquisas. Neste tipo de experimento, um fenômeno tribológico importante que deve ser observado e, considerado, refere-se à obtenção do Regime Permanente de Desgaste, caracterizado pela estabilização do coeficiente de desgaste com o tempo de ensaio. Com isso, o objetivo deste trabalho foi avaliar a obtenção do Regime Permanente de Desgaste em corpos-de-prova de WC-Co P20 e aço-ferramenta M2, por ensaios de desgaste micro-abrasivo por esfera rotativa. Completando o sistema tribológico, foram utilizadas uma esfera de aço AISI 52100 e uma lama abrasiva preparada com carbeto de silício $(\mathrm{SiC})$ preto e água destilada. Um valor de força normal e diferentes valores de tempos de ensaio foram definidos e, durante os experimentos, a lama abrasiva foi, continuamente, agitada e gotejada entre a esfera de ensaio e o corpo-de-prova. Após os ensaios, todas as crateras de desgaste geradas foram analisadas por microscopia óptica, com o intuito de medir os respectivos diâmetros e verificar os modos de desgaste micro-abrasivos atuantes nas superfícies das mesmas. Para as condições de ensaio definidas, observou-se que o Regime Permanente de Desgaste foi obtido junto aos corpos-de-prova de WC-Co P20, visto o comportamento constante do coeficiente de desgaste com a variação do tempo de ensaio, mas não para o aço-ferramenta M2, no qual foi reportada a variação desta mesma grandeza. Finalmente, no presente estudo conclui-se, também, que o Regime Permanente de Desgaste não é uma propriedade do material, sendo este fenômeno fortemente dependente dos materiais que compõe o sistema tribológico e das condições de ensaio impostas.

Palavras-chave: Desgaste micro-abrasivo, desgaste micro-abrasivo por riscamento, desgaste micro-abrasivo por rolamento, Regime Permanente de Desgaste.

\section{ABSTRACT}

Since its introduction to scientific community of tribologists, the micro-abrasive wear test by rotative ball has been adopted by renowned universities and research centers. In this type of experiment, an important tribological phenomenon that must be observed and considered is related to the attainment of the Steady-State of Wear, characterized by stabilization of the coefficient of wear as a function of the test time. In this context, the purpose of this work was to evaluate the attainment of the Steady-State of Wear in specimens of WC-Co P20 and M2 tool-steel, during micro-abrasive wear tests by rotative ball. Completing the tribological system, have been used spheres of AISI 52100 steel and an abrasive slurry prepared with black silicon carbide (SiC) and distilled water. One value of normal force and different values of test times have been defined and, during the experiments, the abrasive slurry has been continuously agitated and dropped between the sphere and the specimen. After testing, all wear craters generated have been analysed by optical microscopy, in order to measure the respective diameters and verify the micro-abrasive wear modes acting on their surfaces. For the established test conditions, it was observed that the Steady-State of Wear has been obtained with the speci- 
men of WC-Co P20, due to the constant behaviour of the coefficient of wear along the test time; however, the Steady-State of Wear has not been obtained for the M2 tool-steel, in which has been observed the variation of the coefficient of wear as a function of the test time. Finally, in this study also has been concluded that the Steady-State of Wear is not a property of the material and this phenomenon is strongly dependent on the materials of the tribological system and of the imposed tests conditions.

Keywords: Micro-abrasive wear, grooving abrasion, rolling abrasion, Steady-State of Wear.

\section{1. INTRODUÇÃO}

A Figura 1 [1] ilustra, de forma esquemática, o princípio do "ensaio de desgaste micro-abrasivo por esfera rotativa".

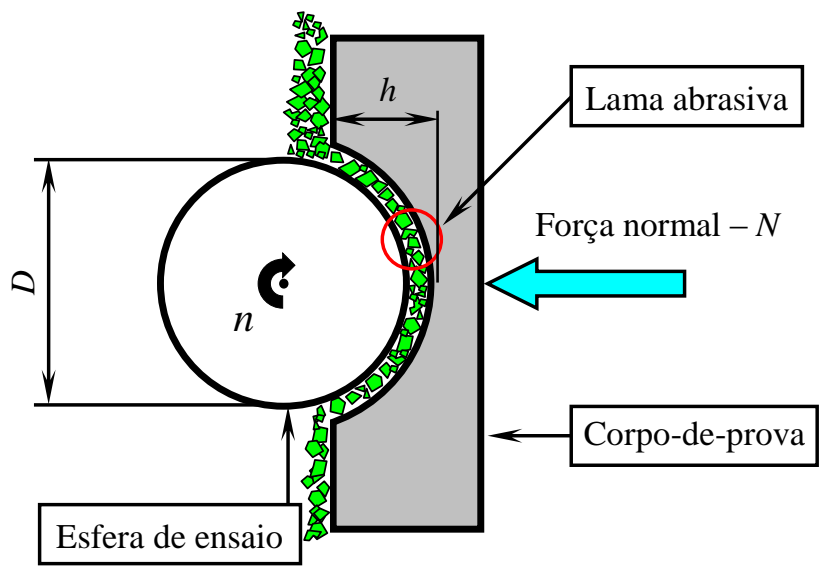

Figura 1: Representação esquemática do princípio do ensaio de desgaste micro-abrasivo por esfera rotativa; " $D$ " é o diâmetro da esfera de ensaio, " $n$ " é a rotação da esfera de ensaio e " $h$ " é a profundidade da cratera de desgaste [1].

Ao lado da esfera de ensaio, que se encontra somente sob movimento de rotação $(n)$, está o corpo-deprova. Durante os ensaios, é inserida uma lama abrasiva, geralmente composta por algum pó abrasivo (por exemplo, carbeto de silício - SiC [1-6]) e água destilada. A aplicação da força normal $(N)$ sobre o corpo-deprova, o contato e o movimento relativo entre os componentes do sistema tribológico geram uma calota esférica no corpo-de-prova, comumente denominada de "cratera de desgaste".

Usualmente, em uma cratera de desgaste, são analisadas duas grandezas geométricas: diâmetro $(d)$ e volume $(V)$. A Figura $2[7,8]$ apresenta estas grandezas; em função de " $d$ " e " $R$ " - raio da esfera de ensaio, o volume da cratera de desgaste $(V)$ pode ser calculado pela Equação $1[9,10]$ :

$$
V \approx \frac{\pi d^{4}}{64 R} \quad \text { para } d<<R
$$
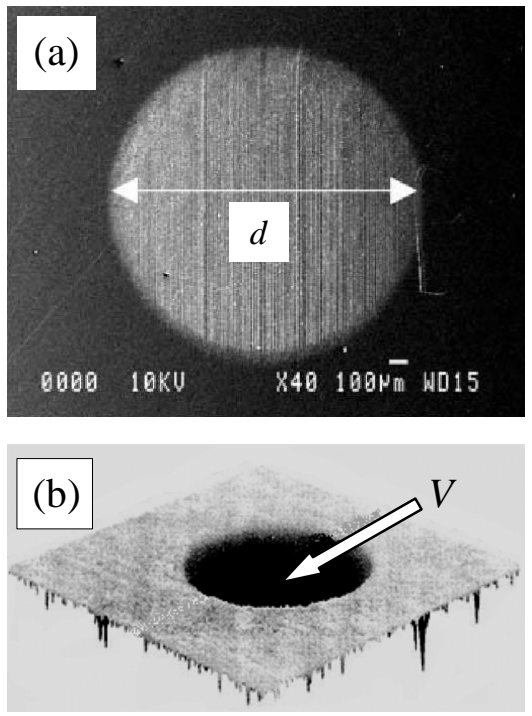

Figura 2: Imagens de crateras de desgaste: (a) diâmetro - $d$ [7] e (b) volume $-V$ [8]. Figura editada. 
Tradicionalmente, o desgaste micro-abrasivo é classificado em dois modos: i) desgaste microabrasivo por riscamento e ii) desgaste micro-abrasivo por rolamento [11-14].

Considerando duas superfícies em movimento relativo, no "desgaste micro-abrasivo por riscamento", as partículas abrasivas estão aderidas (mas, não necessariamente, incrustadas ou fixadas) em uma das superfícies (Figura 3a), sendo possível a elas, somente o movimento de translação ("deslizamento") sobre o contra-corpo. No "desgaste micro-abrasivo por rolamento", as partículas abrasivas estão livres entre as duas superfícies, podendo rolar entre as mesmas (Figura 3b) [11,14].

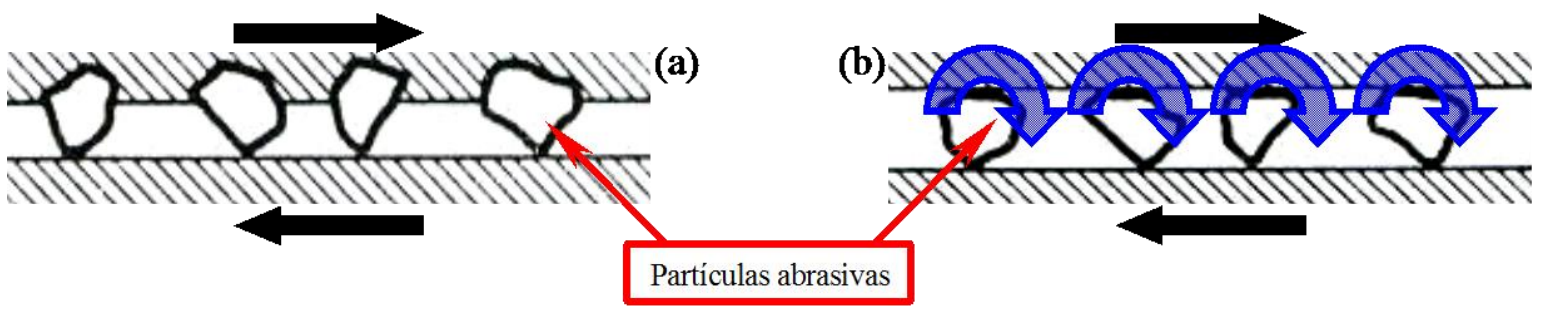

Figura 3: Princípio do (a) desgaste micro-abrasivo por riscamento e do (b) desgaste micro-abrasivo por rolamento (figura editada) $[11,14]$.

As classificações "riscamento" e "rolamento" se baseiam nas marcas de desgaste geradas pelas partículas abrasivas na superfície do corpo-de-prova, como exibe a Figura 4 [2,15].

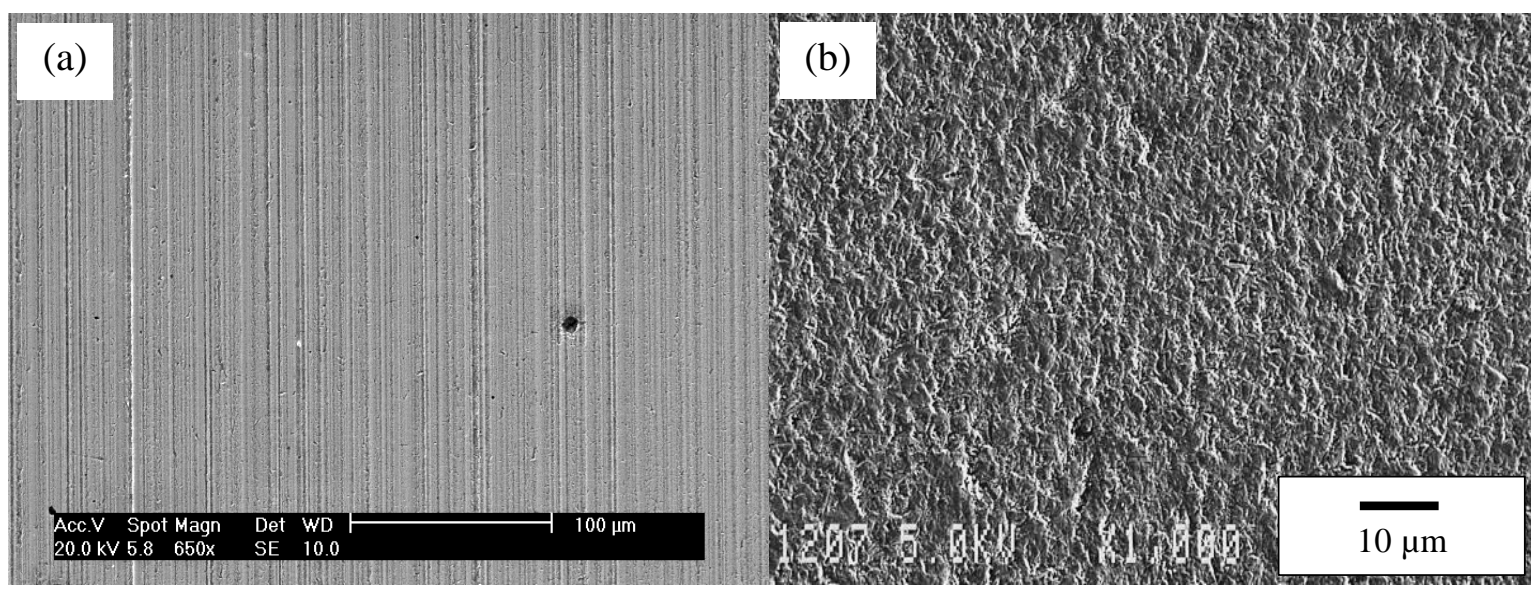

Figura 4: Marcas de (a) desgaste micro-abrasivo por riscamento [2] e (b) desgaste micro-abrasivo por rolamento (figura editada) [15], geradas em ensaios de desgaste micro-abrasivo por esfera rotativa.

Em relação ao comportamento tribológico de materiais, afirma-se que o processo de desgaste atingiu o Regime Permanente de Desgaste $(R P D)$ quando o coeficiente de desgaste $-k$ permanece constante ao longo do tempo [8,16], sendo calculado pela Equação 2 [16]; nesta, $S$ é a distância de deslizamento entre a esfera de ensaio e a superfície do corpo-de-prova.

$$
k=\frac{V}{S . N}
$$

A Figura 5 [17] apresenta exemplos em que o comportamento do coeficiente de desgaste $-k$ tendeu a permanecer constante com a variação do tempo de ensaio - $t$, caracterizando, consequentemente, a obtenção do Regime Permanente de Desgaste. Os termos $k_{t}, k_{s}$ e $k_{c}$ referem-se, respectivamente, ao coeficiente de desgaste total (substrato + revestimento), ao coeficiente de desgaste do substrato e ao coeficiente de desgaste do revestimento ("coating").

Tais resultados [17] foram obtidos a partir de um corpo-de-prova de aço-ferramenta AISI D2, revestido com um filme fino de nitreto de titânio (TiN), com espessura de $2 \mu \mathrm{m}$ [18]. Foi utilizada uma esfera de ensaio de aço-rápido AISI 52100, de diâmetro $D=25,4 \mathrm{~mm}$ (1"), sob uma rotação $n=37,6 \mathrm{rpm}$. A pasta abrasiva foi preparada com partículas abrasivas de carbeto de silício ( $\mathrm{SiC}$ ) preto (tamanho médio de partícula de $a_{p}=5 \mu \mathrm{m}$ ) e água destilada, a uma razão de $C=25 \% \mathrm{SiC}+75 \% \mathrm{H}_{2} \mathrm{O}$ destilada (em volume), que é considerado um valor de concentração de lama abrasiva relativamente elevado [15]. Os ensaios foram conduzidos sob uma força normal de $N=1,25 \mathrm{~N}$. 


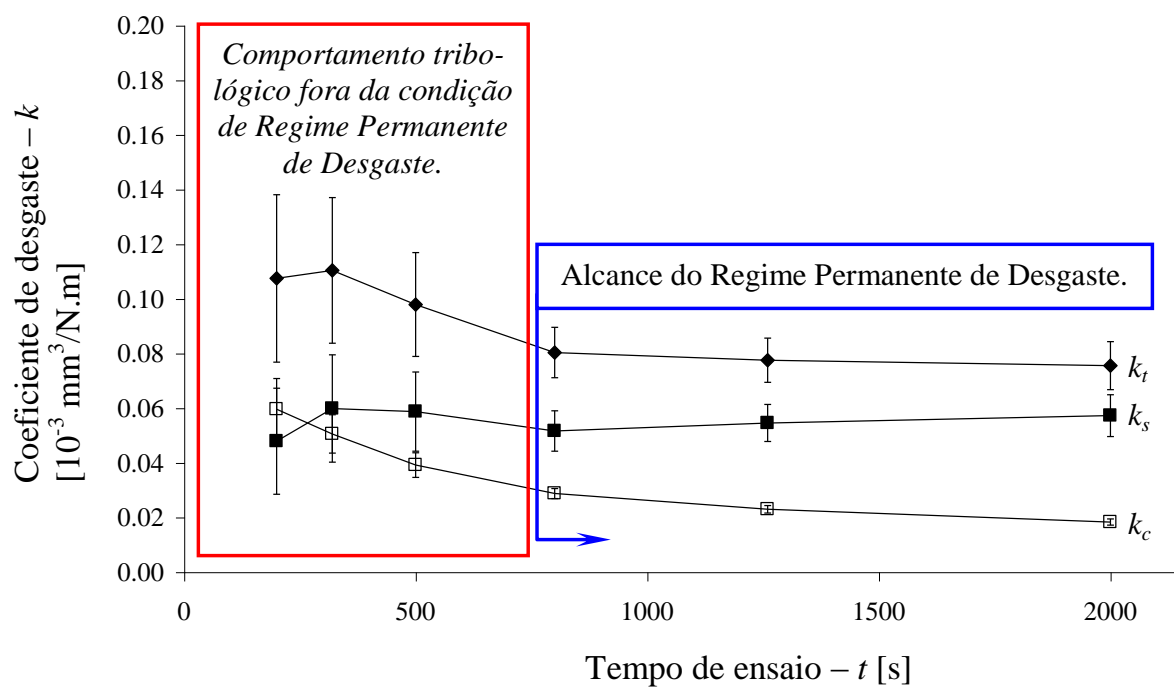

Figura 5: Comportamento do coeficiente de desgaste $(k)$ em função do tempo de ensaio $(t)-k=f(t)$. Indicação da obtenção do Regime Permanente de Desgaste - $R P D$, definido pela estabilização de $k_{t}, k_{s}$ e $k_{c}$. Ensaios realizados em um corpo-de-prova revestido com nitreto de titânio - TiN [17]. Figura editada.

Um ponto importante que deve ser ressaltado refere-se à análise do comportamento de $k$ em função de $t$. Recomenda-se que, antes da obtenção do Regime Permanente de Desgaste - RPD, não sejam formalizadas conclusões sobre a pesquisa desenvolvida, visto que, a priori, o desenvolvimento do processo de desgaste antes do alcance do RPD não apresenta um comportamento previsível.

Com isso, o propósito deste trabalho é estudar a obtenção do Regime Permanente de Desgaste em ensaios de desgaste micro-abrasivo por esfera rotativa conduzidos em corpos-de-prova de WC-Co P20 e açoferramenta M2.

\section{EQUIPAMENTO DE ENSAIO, MATERIAIS E METODOLOGIA EXPERIMENTAL}

\subsection{Equipamento de ensaio}

Nos experimentos deste trabalho foi utilizado um equipamento de ensaio de desgaste micro-abrasivo por esfera rotativa fixa (Figura 6).

Nesta configuração mecânica, inicialmente, a esfera de ensaio, que possui um furo central, é fixada ao eixo de ensaio, por meio de uma porca sextavada e uma arruela de pressão. Durante os ensaios, o corpo-deprova permanece em contato com a esfera de ensaio que, sob movimento de rotação e, com a inserção de lama abrasiva, gera a cratera de desgaste no material em estudo.

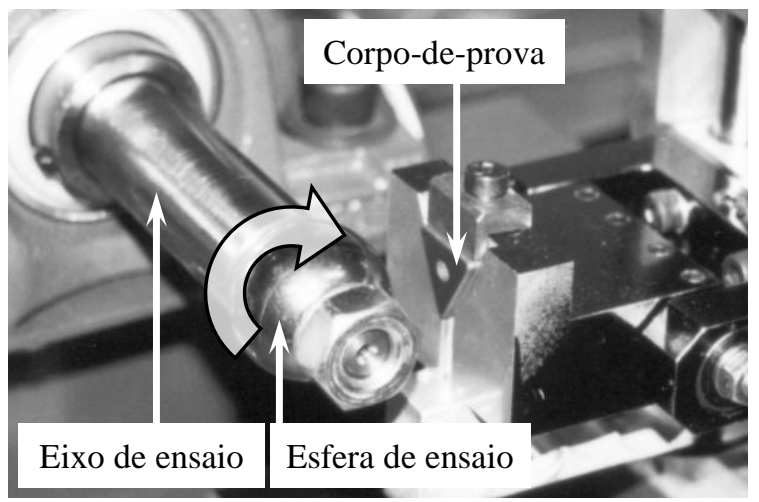

Figura 6: Equipamento de ensaio de desgaste micro-abrasivo por esfera rotativa fixa utilizado neste trabalho.

\subsection{Materiais}

Os corpos-de-prova foram de WC-Co P20 e aço-ferramenta M2 (temperado e revenido).

Para as análises das microestruturas desses materiais, outros corpos-de-prova foram embutidos em baquelita, tendo suas superfícies preparadas com lixas granas \#220, \#320, \#400, \#600 e pastas diamantadas de granulometrias $6 \mu \mathrm{m}, 3 \mu \mathrm{m}$ e $0,25 \mu \mathrm{m}$, nestas ordens. Na sequência, o ataque químico da superfície do 
WC-Co P20 foi realizado com o reagente MURAKAMI e, para a superfície do aço-ferramenta M2, foi utilizado Nital 3\%. A Figura 7a exibe a composição química nominal e a microestrutura do WC-Co P20 e, a Figura $7 \mathrm{~b}$, a composição química nominal e a microestrutura do aço-ferramenta M2.
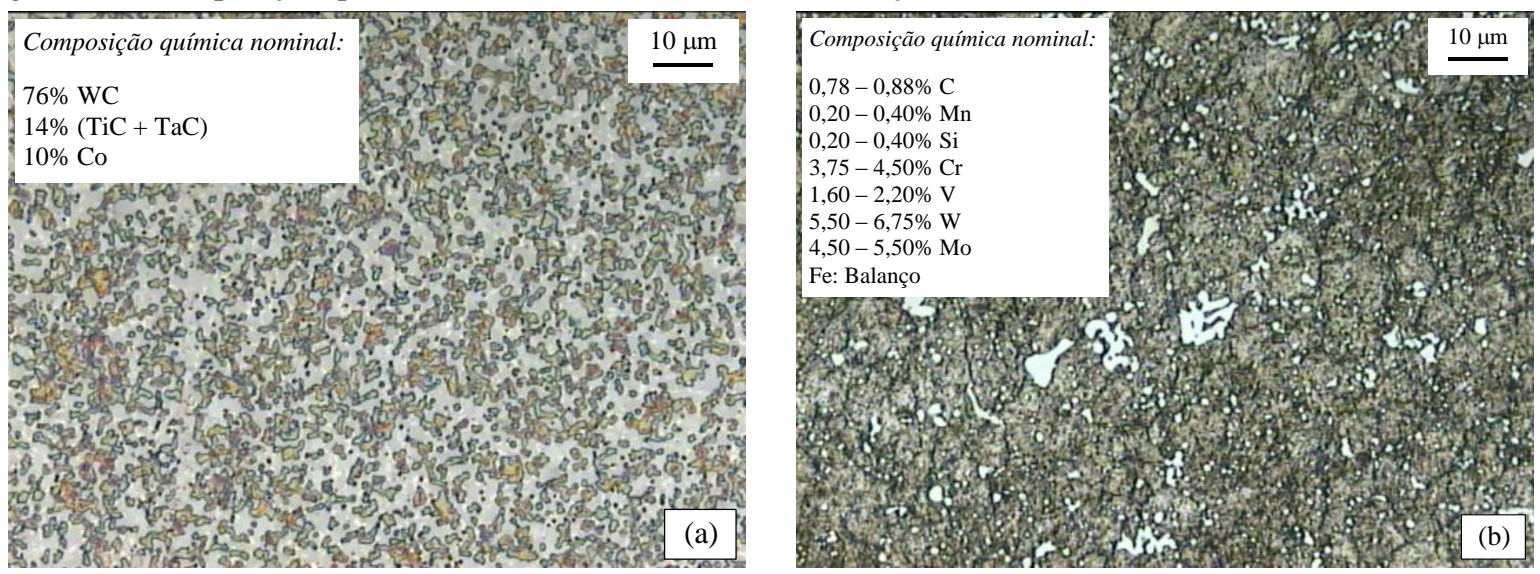

Figura 7: Composição química nominal e microestrutura do (a) WC-Co P20 e do (b) aço-ferramenta M2.

Como contra-corpo, foi utilizada uma esfera de aço AISI 52100 temperado e revenido, de diâmetro $D=25,4 \mathrm{~mm}(D=1$ "). Em uma segunda esfera, utilizada somente para a análise da microestrutura do aço AISI 52100 temperado e revenido, a preparação de sua superfície foi realizada da mesma maneira e com os mesmos materiais utilizados para o aço-ferramenta M2. A Figura 8 mostra a composição química nominal e a microestrutura do aço AISI 52100, na condição metalúrgica temperado e revenido.

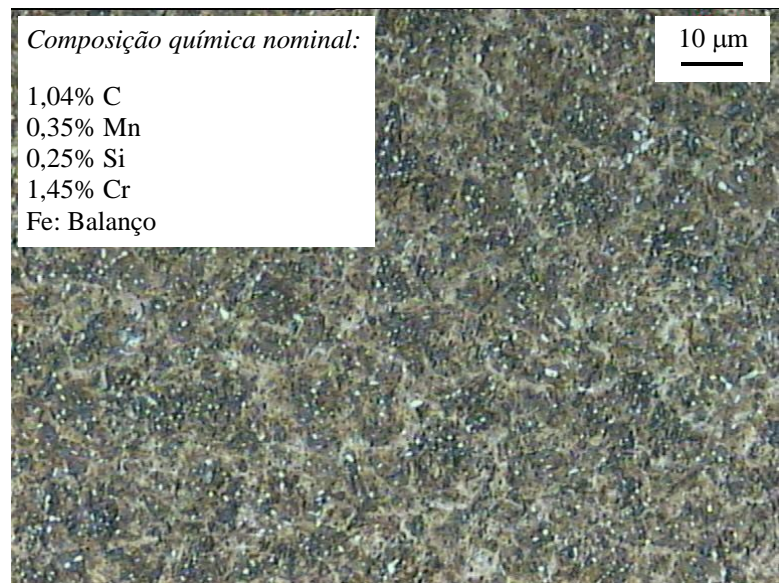

Figura 8: Composição química nominal e microestrutura do aço AISI 52100, na condição metalúrgica temperado e revenido.

A pasta abrasiva foi preparada com carbeto de silício preto - SiC (tamanho médio de partícula abrasiva de $a_{p}=5 \mu \mathrm{m}$ e formato angular), comercial de grau técnico, e água destilada. A Figura 9 apresenta uma Micrografia Eletrônica de Varredura do SiC utilizado (Figura 9a) e sua respectiva distribuição granulométrica (Figura 9b) [19], que relaciona intervalos de valores de tamanhos de partículas abrasivas $\left(a_{p}\right)$ com a porcentagem que compõe o montante de material abrasivo; tais intervalos de valores estão compreendidos entre “0” (zero) à um determinado valor de " $a_{p}$ ”, sendo, de forma matemática, definidos como $\left[0, a_{p}\right]$.
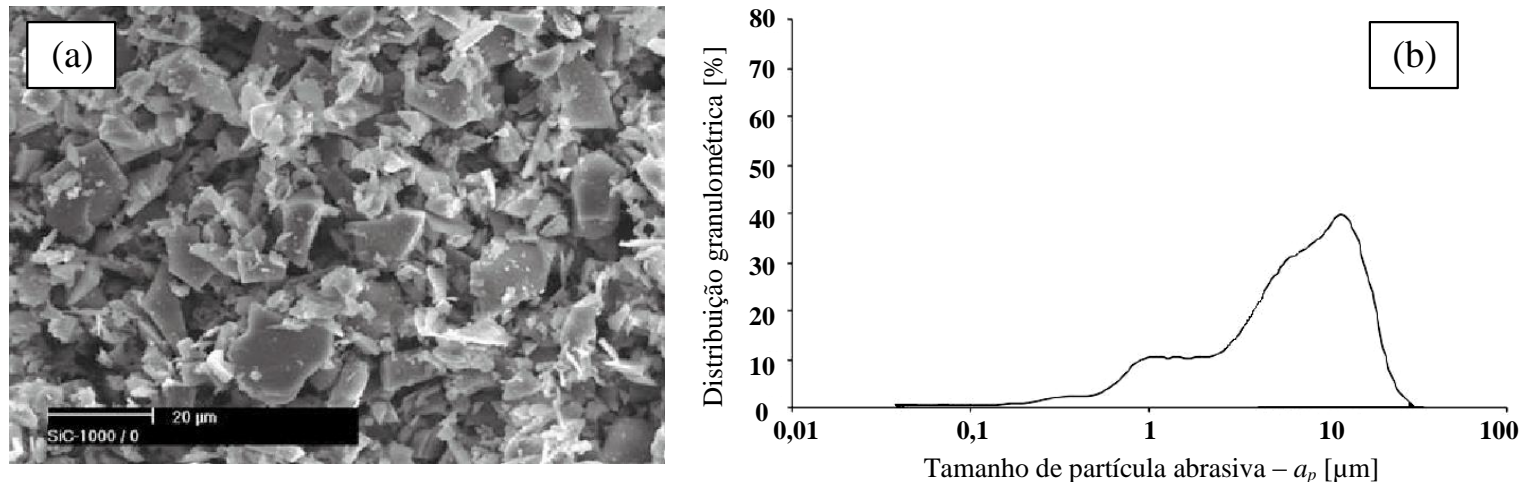

Figura 9: Carbeto de silício preto - SiC: (a) Micrografia Eletrônica de Varredura e (b) distribuição granulométrica [19]. 
Para o cálculo da dureza do SiC, uma porção do material foi sinterizada e dez indentações Vickers foram conduzidas sob uma carga de $50 \mathrm{~N}$ e tempo de $15 \mathrm{~s}$ [19]. Com estes mesmos valores de força e tempo, foram medidas as durezas Vickers dos corpos-de-prova e da esfera de ensaio, por meio de treze indentações realizadas na superfície de cada material; em seguida, descartando-se o valor de dureza obtido na primeira indentação, a dureza de cada material foi determinada pela média aritmética dos dez valores mais próximos entre si. A Tabela 1 reúne os valores das durezas destes materiais.

Tabela 1: Dureza dos materiais utilizados nos ensaios tribológicos.

\begin{tabular}{ccc}
\hline & Material & Dureza - [HV] \\
\hline \multirow{2}{*}{ Corpo-de-prova } & WC-Co P20 & 1193 HV5 \\
\cline { 2 - 3 } & Aço-ferramenta M2 & 652 HV5 \\
\hline Esfera de ensaio & Aço AISI 52100 - temperado e revenido & 856 HV5 \\
\hline Partículas abrasivas & SiC - carbeto de silício preto & 1937 HV5 \\
\hline
\end{tabular}

\subsection{Metodologia Experimental}

A Tabela 2 apresenta as condições de ensaio estabelecidas para os experimentos deste trabalho.

Tabela 2: Valores dos parâmetros de ensaio estabelecidos para os experimentos de desgaste micro-abrasivo.

\begin{tabular}{cccc}
\hline Condição de ensaio & $\mathbf{1}$ & $\mathbf{2}$ & $\mathbf{3}$ \\
\hline Força normal $-N[\mathrm{~N}]$ & \multicolumn{3}{c}{$1,25 *$} \\
\hline Concentração da lama abrasiva $-C[\mathrm{em}$ volume $]$ & \multicolumn{2}{c}{$25 \% \mathrm{SiC}+75 \% \mathrm{H}_{2} \mathrm{O}$ destilada * } \\
\hline Rotação da esfera de ensaio $-n[\mathrm{rpm}]$ & \multicolumn{3}{c}{37,6 * } \\
\hline Distância de deslizamento $-S[\mathrm{~m}]$ & 25 & 35 & 40 \\
\hline Tempo de ensaio $-t[$ min s] & $8 \min 20 \mathrm{~s}$ & 11 min $40 \mathrm{~s}$ & 13 min $20 \mathrm{~s}$ \\
\hline
\end{tabular}

* Valores comuns para as três condições de ensaios.

Baseado na publicação de Trezona et al. [15], foi estabelecido o valor de força normal de $N=1,25 \mathrm{~N}$, junto ao valor de concentração de lama abrasiva de $C=25 \% \mathrm{SiC}+75 \%$ de $\mathrm{H}_{2} \mathrm{O}$ destilada (em volume).

A rotação da esfera de ensaio foi de $n=37,6 \mathrm{rpm}$ e, com um valor de diâmetro da esfera de ensaio de $D=25,4 \mathrm{~mm}$, tem-se uma velocidade tangencial de $v=0,05 \mathrm{~m} / \mathrm{s}$, o que elimina efeitos hidrodinâmicos decorrentes da inserção da lama abrasiva entre a esfera de ensaio e o corpo-de-prova durante os experimentos $[20,21]$.

Três valores de distâncias de deslizamento $(S)$ foram definidos: $S_{1}=25 \mathrm{~m}, S_{2}=35 \mathrm{~m}$ e $S_{3}=40 \mathrm{~m}$. Junto ao valor de $v=0,05 \mathrm{~m} / \mathrm{s}$, foram calculados os tempos de ensaios $(t)$ necessários a condução dos experimentos: $t_{1}=8 \min 20 \mathrm{~s}\left(t_{1}=500 \mathrm{~s}\right), t_{2}=11 \min 40 \mathrm{~s}\left(t_{2}=700 \mathrm{~s}\right)$ e $t_{3}=13 \min 20 \mathrm{~s}\left(t_{3}=800 \mathrm{~s}\right)$, respectivamente.

Todos os ensaios foram conduzidos sem paradas intermediárias e a lama abrasiva foi, continuamente, agitada e gotejada entre a esfera de ensaio e o corpo-de-prova, sob uma frequência de $f_{g} \approx 1$ gota $/ 2 \mathrm{~s}$. Para cada condição de ensaio, foram conduzidas quatro repetições.

\subsection{Análise qualitativa e quantitativa das atuações dos modos de desgaste micro-abrasivos nas crate- ras de desgaste}

O conhecimento dos modos de desgaste micro-abrasivos atuantes nas superfícies das crateras de desgaste fazse necessário, visto que estes podem influenciar a reprodutibilidade dos resultados gerados [22].

Com isso, com o objetivo de registrar as ocorrências de desgaste micro-abrasivo por "riscamento" e/ou "rolamento", após as finalizações de todos os ensaios de desgaste micro-abrasivo por esfera rotativa fixa, a primeira etapa de análise de resultados foi a verificação dos modos de desgaste micro-abrasivos atuantes nas superfícies das crateras de desgaste.

A condução destas análises iniciaram-se a partir de imagens obtidas por Microscopia Óptica. Posteriormente, todas as imagens das crateras de desgaste foram transferidas para um software de CAD, no qual realizaram-se, para cada cratera desgastada e, com o auxílio de comandos apropriados, as medições da área projetada total da cratera de desgaste $-A_{t}$ e da área de atuação de desgaste micro-abrasivo por riscamento $A_{g}$. Em seguida, adotando-se o mesmo procedimento definido por R.C. Cozza em um trabalho anterior [23], a área de atuação de desgaste micro-abrasivo por rolamento $-A_{r}$ foi calculada pela Equação 3:

$$
A_{r}=A_{t}-A_{g}
$$


Finalizando esta etapa de análise, foram calculadas, para cada cratera de desgaste, as grandezas " $\% A_{g}$ " e “\% $A_{r}$ ", pelas Equações 4 e 5, respectivamente.

$$
\begin{aligned}
& \% A_{g}=\frac{A_{g}}{A_{t}} 100 \% \\
& \% A_{r}=\frac{A_{r}}{A_{t}} 100 \%
\end{aligned}
$$

“\% $A_{g}$ " e "\% $A_{r}$ " são parâmetros de análise definidos como sendo, respectivamente, a "porcentagem de atuação de desgaste micro-abrasivo por "riscamento" na superfície da cratera de desgaste" e a "porcentagem de atuação de desgaste micro-abrasivo por "rolamento" na superfície da cratera de desgaste".

\subsection{Análise experimental e estatística da obtenção do Regime Permanente de Desgaste - RPD}

A segunda etapa de análise de resultados conduzida no Microscópio Óptico foram as medições dos diâmetros (d) de cada cratera de desgaste, conforme o exposto na Figura 2a [7].

Seguindo, ainda, a revisão da literatura introduzida, com os valores dos diâmetros $-d$, o volume $-V$ de cada cratera de desgaste produzida foi calculado a partir da Equação 1 e, então, o coeficiente de desgaste $k$ foi determinado pela Equação 2 .

Em sequência, as análises das obtenções das condições de Regime Permanente de Desgaste para os materiais de WC-Co P20 e aço-ferramenta M2 foram conduzidas com base nos comportamentos dos gráficos do coeficiente de desgaste $(k)$ em função do tempo de ensaio $(t)-k=f(t)$.

Finalmente, em função das quatro repetições conduzidas para cada condição de ensaio estabelecida, os respectivos desvios-padrão dos valores dos coeficientes de desgaste $-k\left(D P_{k}\right)$ foram calculados e inseridos nos gráficos de $k=f(t)$.

\section{RESULTADOS E DISCUSSÃO}

\subsection{Análise das crateras de desgaste e dos modos de desgaste micro-abrasivos atuantes}

A Figura 10 apresenta crateras de desgaste representativas dos resultados obtidos durante esta pesquisa. A Figura 10a refere-se a uma cratera de desgaste produzida em um corpo-de-prova de WC-Co P20 e, a Figura $10 \mathrm{c}$, em um corpo-de-prova de aço-ferramenta M2.

Observa-se que, para ambos os materiais de corpos-de-prova, qualitativamente, foram geradas crateras de desgaste possíveis de serem definidos valores precisos de diâmetros $-d$, devido ao formato circular das mesmas e, também, pelo fato de não ter ocorrido "scuffing" [24]. "Scuffing" é um fenômeno conceituado como riscos que ocorrem na borda da cratera de desgaste, na direção de deslizamento da esfera de ensaio e que podem ocasionar a perda de precisão da medida do diâmetro da cratera de desgaste.

Além disso, foi reportado que nas crateras de desgaste ocorreu, predominantemente, a atuação de desgaste micro-abrasivo por rolamento, como pode ser observado nas Figuras 10b e 10d, para os corpos-deprova de WC-Co P20 e aço-ferramenta M2, respectivamente, contribuindo, consequentemente, para a reprodutibilidade dos resultados obtidos.

Para os corpos-de-prova de WC-Co P20 e aço-ferramenta M2, as Tabelas 3 e 4 apresentam, respectivamente, para cada cratera de desgaste, os valores do diâmetro $-d$, da área projetada total $-A_{t}$, da área de atuação de desgaste micro-abrasivo por riscamento $-A_{g}$ e da área de atuação de desgaste micro-abrasivo por rolamento $-A_{r}$. Adicionalmente, são informados, também, os valores das grandezas " $\% A_{g}$ " e " $\% A_{r}$ "

Em relação à reprodutibilidade de resultados, em ensaios de desgaste micro-abrasivo por esfera rotativa, é importante que ocorra a atuação de desgaste micro-abrasivo por rolamento, visto que, este modo de desgaste micro-abrasivo proporciona resultados de melhor confiabilidade estatística, conforme publicado por Bose e Wood [22]. Com isso, pela literatura [22] e pelas análises estatísticas conduzidas e referenciadas quanto aos comportamentos dos desvios-padrão $\left(D P_{k}\right)$, pode-se dizer que os valores de $k$ apresentados no próximo tópico (Item 3.2 Análise da obtenção do Regime Permanente de Desgaste - RPD), necessários ao estudo da obtenção do Regime Permanente de Desgaste para os materiais e condições de ensaio em questão, apresentam confiabilidade estatística e científica, podendo, assim, serem discutidos em sua plenitude. 


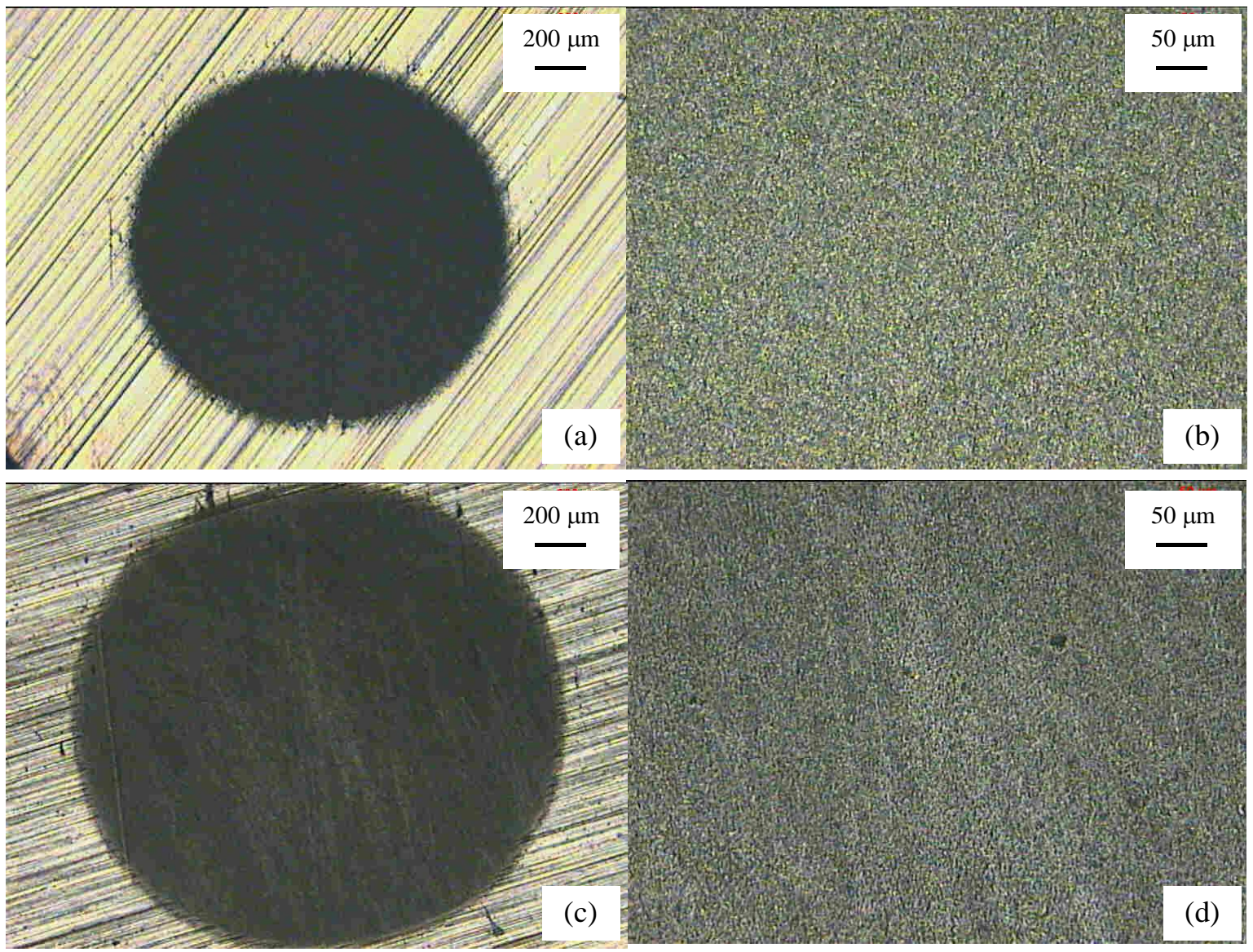

Figura 10: Crateras de desgaste geradas nos corpos-de-prova de (a)-(b) WC-Co P20 e (c)-(d) aço-ferramenta M2, com atuação de desgaste micro-abrasivo por rolamento em ambos os casos. Tempo de ensaio de $t_{3}=13 \mathrm{~min} 20 \mathrm{~s}$.

Tabela 3: Corpos-de-prova de WC-Co P20 - valores dos diâmetros das crateras de desgaste $-d$, das áreas projetadas totais das crateras de desgaste $-A_{t}$, das áreas de atuações de desgaste micro-abrasivo por riscamento $-A_{g}$, das áreas de atuações de desgaste micro-abrasivo por rolamento $-A_{r}$, das porcentagens de atuações de desgaste micro-abrasivo por "riscamento" nas superfícies das crateras de desgaste $-\% A_{g}$ " e das porcentagens de atuações de desgaste micro-abrasivo por "rolamento" nas superfícies das crateras de desgaste $-\% A_{r}$.

\begin{tabular}{|c|c|c|c|c|c|}
\hline$S[\mathrm{~m}]$ & Grandeza & Ensaio 1 & Ensaio 2 & Ensaio 3 & Ensaio 4 \\
\hline \multirow{6}{*}{25} & $d \quad[\mathrm{~mm}]$ & 1,387 & 1,383 & 1,364 & 1,376 \\
\hline & $A_{t}\left[\mathrm{~mm}^{2}\right]$ & 1,512 & 1,502 & 1,462 & 1,487 \\
\hline & $A_{g}\left[\mathrm{~mm}^{2}\right]$ & 0 & 0 & 0 & 0 \\
\hline & $A_{r}\left[\mathrm{~mm}^{2}\right]$ & 1,512 & 1,502 & 1,462 & 1,487 \\
\hline & $\% A_{g}$ & 0 & 0 & 0 & 0 \\
\hline & $\% A_{r}$ & 100 & 100 & 100 & 100 \\
\hline \multirow{6}{*}{35} & $d \quad[\mathrm{~mm}]$ & 1,522 & 1,592 & 1,472 & 1,470 \\
\hline & $A_{t}\left[\mathrm{~mm}^{2}\right]$ & 1,820 & 1,991 & 1,702 & 1,698 \\
\hline & $A_{g}\left[\mathrm{~mm}^{2}\right]$ & 0 & 0 & 0 & 0 \\
\hline & $A_{r}\left[\mathrm{~mm}^{2}\right]$ & 1,820 & 1,991 & 1,702 & 1,698 \\
\hline & $\% A_{g}$ & 0 & 0 & 0 & 0 \\
\hline & $\% A_{r}$ & 100 & 100 & 100 & 100 \\
\hline \multirow{6}{*}{40} & $d \quad[\mathrm{~mm}]$ & 1,467 & 1,542 & 1,636 & 1,594 \\
\hline & $A_{t}\left[\mathrm{~mm}^{2}\right]$ & 1,691 & 1,867 & 2,101 & 1,995 \\
\hline & $A_{g}\left[\mathrm{~mm}^{2}\right]$ & 0 & 0 & 0 & 0 \\
\hline & $\begin{array}{ll}A_{r} & {\left[\mathrm{~mm}^{2}\right]} \\
\end{array}$ & 1,691 & 1,867 & 2,101 & 1,995 \\
\hline & $\% A_{g}$ & 0 & 0 & 0 & 0 \\
\hline & $\% A_{r}$ & 100 & 100 & 100 & 100 \\
\hline
\end{tabular}


Tabela 4: Corpos-de-prova de aço-ferramenta M2 - valores dos diâmetros das crateras de desgaste - $d$, das áreas projetadas totais das crateras de desgaste $-A_{t}$, das áreas de atuações de desgaste micro-abrasivo por riscamento $-A_{g}$, das áreas de atuações de desgaste micro-abrasivo por rolamento $-A_{r}$, das porcentagens de atuações de desgaste micro-abrasivo por "riscamento" nas superfícies das crateras de desgaste $-\% A_{g}$ " e das porcentagens de atuações de desgaste micro-abrasivo por "rolamento" nas superfícies das crateras de desgaste $-\% A_{r}$.

\begin{tabular}{|c|c|c|c|c|c|}
\hline$S[\mathrm{~m}]$ & Grandeza & Ensaio 1 & Ensaio 2 & Ensaio 3 & Ensaio 4 \\
\hline \multirow{6}{*}{25} & $d \quad[\mathrm{~mm}]$ & 1,455 & 1,487 & 1,458 & 1,477 \\
\hline & $A_{t}\left[\mathrm{~mm}^{2}\right]$ & 1,663 & 1,737 & 1,670 & 1,713 \\
\hline & $A_{g}\left[\mathrm{~mm}^{2}\right]$ & 0,455 & 0,660 & 0,682 & 0,578 \\
\hline & $A_{r}\left[\mathrm{~mm}^{2}\right]$ & 1,208 & 1,077 & 0,988 & 1,135 \\
\hline & $\% A_{g}$ & $27,36 \%$ & $38 \%$ & $40,84 \%$ & $33,74 \%$ \\
\hline & $\% A_{r}$ & $72,64 \%$ & $62 \%$ & $59,16 \%$ & $66,26 \%$ \\
\hline \multirow{6}{*}{35} & $d \quad[\mathrm{~mm}]$ & 1,426 & 1,507 & 1,391 & 1,451 \\
\hline & $A_{t}\left[\mathrm{~mm}^{2}\right]$ & 1,597 & 1,784 & 1,520 & 1,654 \\
\hline & $A_{g}\left[\mathrm{~mm}^{2}\right]$ & 0 & 0 & 0 & 0 \\
\hline & $A_{r}\left[\mathrm{~mm}^{2}\right]$ & 1,597 & 1,784 & 1,520 & 1,654 \\
\hline & $\% A_{g}$ & 0 & 0 & 0 & 0 \\
\hline & $\% A_{r}$ & $100 \%$ & $100 \%$ & $100 \%$ & $100 \%$ \\
\hline \multirow{6}{*}{40} & $d[\mathrm{~mm}]$ & 1,911 & 1,955 & 1,990 & 1,994 \\
\hline & $A_{t}\left[\mathrm{~mm}^{2}\right]$ & 2,868 & 3,002 & 3,110 & 3,123 \\
\hline & $A_{g}\left[\mathrm{~mm}^{2}\right]$ & 0 & 0 & 0 & 0 \\
\hline & $A_{r}\left[\mathrm{~mm}^{2}\right]$ & 2,868 & 3,002 & 3,110 & 3,123 \\
\hline & $\% A_{g}$ & 0 & 0 & 0 & 0 \\
\hline & $\% A_{r}$ & $100 \%$ & $100 \%$ & $100 \%$ & $100 \%$ \\
\hline
\end{tabular}

\subsection{Análise da obtenção do Regime Permanente de Desgaste - RPD}

A Figura 11 apresenta o comportamento do coeficiente de desgaste $(k)$ em função do tempo de ensaio $(t)-$ $k=f(t)$, para o WC-Co P20 e para o aço-ferramenta M2.

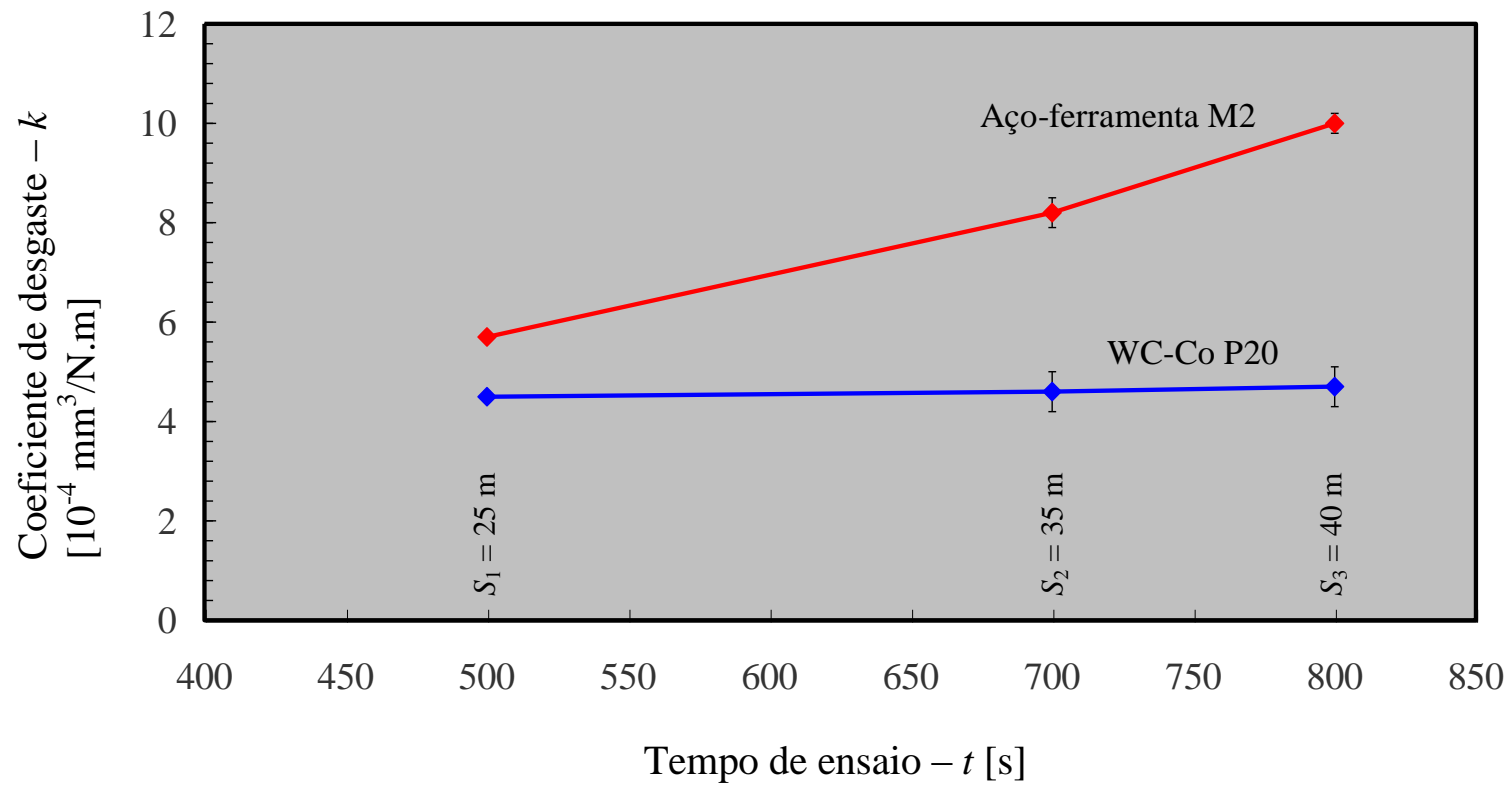

Figura 11: Comportamento do coeficiente de desgaste $(k)$ em função do tempo de ensaio $(t)-k=f(t)$, para os corpos-deprova de WC-Co P20 e aço-ferramenta M2. 
Para o WC-Co P20, os resultados obtidos indicam que o Regime Permanente de Desgaste foi obtido, pois o coeficiente de desgaste $(k)$ alcançou uma condição de estabilidade com a variação do tempo de ensaio $(t)$.

Em relação ao aço-ferramenta M2, conclui-se que o Regime Permanente de Desgaste não foi alcançado, visto que, até o tempo de ensaio de $t_{3}=13 \min 20 \mathrm{~s}$, o coeficiente de desgaste $(k)$ não apresentou tendência de estabilidade com o aumento do tempo de ensaio $(t)$.

Como exemplo deste comportamento tribológico apresentado por materiais sob incidência de desgaste micro-abrasivo por esfera rotativa, cita-se os ensaios conduzidos por Silva et al. $[8,25,26]$ que, nas referidas publicações, reportaram o comportamento ao desgaste micro-abrasivo de materiais sinterizados sob uma força normal de $N=0,22 \mathrm{~N}$, inserindo, entre o corpo-de-prova e a esfera de ensaio, diferentes materiais de partículas abrasivas (hematita $-\mathrm{Fe}_{2} \mathrm{O}_{3}$, sílica $-\mathrm{SiO}_{2}$ e alumina $-\mathrm{Al}_{2} \mathrm{O}_{3}$ ); a esfera de ensaio, fabricada de aço para rolamento, possuía diâmetro $D=20 \mathrm{~mm}$ e trabalhou sob uma rotação de $n=150 \mathrm{rpm}$. Os referidos pesquisadores reportaram que o processo de desgaste entrou em Regime Permanente de Desgaste a partir de um tempo de ensaio de, aproximadamente, $t=2 \min 20 \mathrm{~s}$.

Além deste, no clássico trabalho publicado por Trezona et al. [15], utilizando corpos-de-prova de açoferramenta, partículas abrasivas de carbeto de silício - SiC e uma esfera de ensaio de aço para rolamento com diâmetro $D=25,4 \mathrm{~mm}$, o processo de desgaste entrou em Regime Permanente de Desgaste sob um tempo de ensaio de $t=5 \min 20 \mathrm{~s}$.

Pelos resultados tomados como referência para a realização da presente pesquisa, observa-se que, em ensaios de desgaste micro-abrasivo por esfera rotativa, para a obtenção do Regime Permanente de Desgaste, em princípio, não existe um valor de tempo de ensaio característico ou, uma faixa de valores, a partir da qual, o processo de desgaste entre em tendência de estabilidade. Na realidade, fortalecendo fatos reportados e publicados pelo autor - R.C. Cozza [27] e, também, por outros pesquisadores [8,25,26], conclui-se que este fenômeno é dependente das propriedades e características mecânicas e tribológicas dos materiais envolvidos (corpo-de-prova, partículas abrasivas e esfera de ensaio) e das condições de ensaio estabelecidas.

\subsubsection{Importância da obtenção do Regime Permanente de Desgaste em ensaios de desgaste micro- abrasivo por esfera rotativa}

Dependendo da situação, o pesquisador pode, antes do início dos ensaios definitivos, conduzir experimentos preliminares para que, em função do próprio sistema tribológico e das condições de ensaio definidas, seja determinado o tempo a partir do qual o processo de desgaste entre em regime de estabilidade.

Este procedimento experimental faz-se necessário visto que, antes do ponto a partir do qual o sistema tribológico atinge a condição de Regime Permanente de Desgaste, a variação do coeficiente de desgaste em função do tempo de ensaio $(k=f(t))$ pode vir apresentar comportamento não-previsível. Consequentemente, os eventos tribológicos que podem ocorrer no material em estudo são aleatórios, tendenciando o pesquisador a reportar resultados precipitados e, com isso, expor conclusões errôneas ou, relativamente pouco precisas sobre a pesquisa conduzida.

Como exemplo do exposto, referenciando-se, na Figura 5, uma situação em que, ao invés do pesquisador ter traçado o comportamento do coeficiente de desgaste $-k$ em função do tempo de ensaio $-t$, tenha, somente, levantado o valor de $k$ para $t=500 \mathrm{~s}$, é possível observar que, para os materiais utilizados e condições de ensaios estabelecidas, o processo de desgaste está fora da faixa de Regime Permanente de Desgaste. Com isso, os modos de desgaste micro-abrasivos atuantes podem diferir quando comparados dentro uma condição de estabilidade tribológica.

\section{CONCLUSÕES}

A seguir, são apresentadas as conclusões deste estudo, que versou sobre a obtenção do Regime Permanente de Desgaste em ensaios de desgaste micro-abrasivo por esfera rotativa, conduzidos em corpos-de-prova de WC-Co P20 e aço-ferramenta M2:

1) Para as condições de ensaio estabelecidas neste estudo, conclui-se que o processo de desgaste atingiu o Regime Permanente de Desgaste junto ao WC-Co P20, em virtude da constância característica do comportamento do coeficiente de desgaste $(k)$ em função do tempo de ensaio $(\mathrm{t})-k=f(t)$; 
2) Em relação ao aço-ferramenta M2, o processo de desgaste não atingiu o Regime Permanente de Desgaste, visto a não-estabilização do comportamento do coeficiente de desgaste $-k$ com o aumento do tempo de ensaio - $t$;

3) O Regime Permanente de Desgaste não é uma propriedade dos materiais. Na realidade, este fenômeno pode ser entendido como um(a) comportamento/característica intrínseco(a) apresentado pelo próprio material quando submetido a determinadas condições tribológicas. Com isso, sob condições tribológicas idênticas, o tempo de ensaio para o qual o Regime Permanente de Desgaste é obtido pode diferir em função do material;

4) O tempo de ensaio - $t$ no qual o processo de desgaste atinge a condição de estabilidade, isto é, o Regime Permanente de Desgaste, deve ser determinado durante a condução dos próprios experimentos, de forma prática;

5) Os resultados obtidos, além de expandir o conhecimento acerca do comportamento ao desgaste micro-abrasivo dos materiais estudados, atesta a importância do estabelecimento do Regime Permanente de Desgaste para a transferabilidade dos resultados para aplicações reais. Caso contrário, previsões de vida ao desgaste micro-abrasivo não seriam viáveis e/ou acuradas, visto as aleatoriedades das ocorrências de fenômenos tribológicos nas crateras de desgaste.

\section{AGRADECIMENTOS}

Ao Sr. José Carlos Cavale - FEROSÃO J.C.R. Indústria e Comércio Ltda., pela usinagem dos corpos-deprova de aço-ferramenta M2.

À amiga Raquel Camponucci - Laboratório de Fenômenos de Superfície - Escola Politécnica da Universidade de São Paulo - LFS-USP, pela ajuda e orientação com as análises metalográficas e ensaios de dureza dos corpos-de-prova de WC-Co P20, aço-ferramenta M2 e da esfera de aço AISI 52100.

Ao Prof. Dr. José Carlos Bressiani - Instituto de Pesquisas Energéticas e Nucleares - Universidade de São Paulo - IPEN-USP, pela doação e caracterização do carbeto de silício - SiC.

\section{BIBLIOGRAFIA}

[1] COZZA, R.C., RODRIGUES, L.C., SCHÖN, C.G., "Analysis of the micro-abrasive wear behavior of an iron aluminide alloy under ambient and high-temperature conditions", Wear, v. 330-331, pp. 250-260, 2015.

[2] COZZA, R.C., TANAKA, D.K., SOUZA, R.M., "Friction coefficient and abrasive wear modes in ballcratering tests conducted at constant normal force and constant pressure - Preliminary results", Wear, v. 267, pp. 61-70, 2009.

[3] BATISTA, J.C.A., GODOY, C., MATTHEWS, A., "Micro-scale abrasive wear testing of duplex and non-duplex (single-layered) PVD (Ti,Al)N, TiN and Cr-N coatings", Tribology International, v. 35, pp. 363$372,2002$.

[4] BATISTA, J.C.A., JOSEPH, M.C., GODOY, C., et al., "Micro-abrasion wear testing of PVD TiN coatings on untreated and plasma nitrided AISI H13 steel”, Wear, v. 249, pp. 971-979, 2002.

[5] BATISTA, J.C.A., MATTHEWS, A., GODOY, C., "Micro-abrasive wear of PVD duplex and singlelayered coatings", Surface and Coatings Technology, v. 142-144, pp. 1137-1143, 2001.

[6] BELLO, J.O., WOOD, R.J.K., "Grooving micro-abrasion of polyamide 11 coated carbon steel tubulars for downhole application”, Wear, v. 255, pp. 1157-1167, 2003.

[7] KELLY, D.A., HUTCHINGS, I.M., "A new method for measurement of particle abrasivity", Wear, v. 250, pp. 76-80, 2001.

[8] SILVA, W.M., Efeito da pressão de compactação e tamanho do pó de ferro na micro-abrasão do ferro sinterizado a vapor, Dissertação de M.Sc, Universidade Federal de Uberlândia, Uberlândia - MG, Brasil, 2003.

[9] RUTHERFORD, K.L., HUTCHINGS, I.M., "Theory and application of a micro-scale abrasive wear test", Journal of Testing and Evaluation - JTEVA, v. 25, n. 2, pp. 250-260, 1997. 
[10] HUTCHINGS, I.M., "Abrasive and erosive wear tests for thin coatings: a unified approach", Tribology International, v. 31, n. 1-3, pp. 5-15, 1998.

[11] HUTCHINGS, I.M. Tribology - Friction and Wear of Engineering Materials, $7^{\text {th }}$ Edition, London - UK, Edward Arnold, a division of Hodder Headline PLC, 1992.

[12] AXÉN, N., JACOBSON, S., HOGMARK, S. "Influence of hardness of the counterbody in three-body abrasive wear - an overlooked hardness effect”, Tribology International, v. 27, n. 4, pp. 233-241, 1994.

[13] COZZA, R.C., DE MELLO, J.D.B., TANAKA, D.K., et al., "Relationship between test severity and wear mode transition in micro-abrasive wear tests", Wear, v. 263, pp. 111-116, 2007.

[14] HUTCHINGS, I.M., "Mechanisms of wear in powder technology: a review", Powder Technology, v. 76, pp. 3-13, 1993.

[15] TREZONA, R.I., ALLSOPP, D.N., HUTCHINGS, I.M. "Transitions between two-body and three-body abrasive wear: influence of test conditions in the microscale abrasive wear test", Wear, v. 225-229, pp. 205$214,1999$.

[16] COZZA, R.C. Estudo do comportamento do coeficiente de desgaste e dos modos de desgaste abrasivo em ensaios de desgaste micro-abrasivo, Dissertação de M.Sc, Universidade de São Paulo, São Paulo - SP, Brasil, 2006.

[17] COZZA, R.C. "A study on friction coefficient and wear coefficient of coated systems submitted to micro-scale abrasion tests”, Surface and Coatings Technology, v. 215, pp. 224-233, 2013.

[18] RECCO, A.A.C. "Estudo da obtenção e das propriedades dos filmes de TiN e TiC depositados sobre aços ferramentas AISI H13 e D2 nitretados e não nitretados”, Tese de D.Sc, Universidade de São Paulo, São Paulo - SP, Brasil, 2008

[19] IZHEVSKYI, V.A., GENOVA, L.A., BRESSIANI, J.C., et al., "Liquid phase sintered SiC ceramics from starting materials of different grade", Cerâmica, v. 50, pp. 261-267, 2004.

[20] ADACHI, K., HUTCHINGS, I.M. "Wear-mode mapping for the micro-scale abrasion test", Wear, v. 255, pp. 23-29, 2003.

[21] ADACHI, K., HUTCHINGS, I.M. "Sensitivity of wear rates in the micro-scale abrasion test to test conditions and material hardness", Wear, v. 258, pp. 318-321, 2005.

[22] BOSE, K., WOOD, R.J.K. "Optimun tests conditions for attaining uniform rolling abrasion in ball cratering tests on hard coatings", Wear, v. 258, pp. 322-332, 2005.

[23] COZZA, R.C., "Effect of pressure on abrasive wear mode transitions in micro-abrasive wear tests of WC-Co P20”, Tribology International, v. 57, pp. 266-271, 2013.

[24] GEE, M.G., GANT, A.J., HUTCHINGS, I.M., BETHKE, R., et al., "Progress towards standardisation of ball cratering", Wear, v. 255, pp. 1-13, 2003.

[25] SILVA, W.M., BINDER, R., DE MELLO, J.D.B. “Abrasive wear of steam-treated sintered iron”, Wear, v. 258, pp. 166-177, 2005.

[26] SILVA, W.M., BINDER, R., DE MELLO, J.D.B. "Microabrasão do ferro sinterizado e oxidado a vapor: mecanismos de desgaste", Tecnologia em Metalurgia e Materiais, São Paulo, v.2, n.2, pp. 39-44, out.-dez. 2005.

[27] COZZA, R.C. Estudo do desgaste e atrito em ensaios micro-abrasivos por esfera rotativa fixa em condições de força normal constante e pressão constante, Tese de D.Sc, Universidade de São Paulo, São Paulo SP, Brasil, 2011.

\section{APÊNDICE}

Nesta seção, é apresentada uma lista de símbolos, com suas respectivas unidades, utilizados neste trabalho.

$a_{p} \quad$ Tamanho médio de partícula abrasiva $[\mu \mathrm{m}]$

$A_{g} \quad$ Área de atuação de desgaste micro-abrasivo por riscamento [ $\left.\mathrm{mm}^{2}\right]$

$A_{r} \quad$ Área de atuação de desgaste micro-abrasivo por rolamento [ $\left.\mathrm{mm}^{2}\right]$

$A_{t} \quad$ Área projetada total da cratera de desgaste $\left[\mathrm{mm}^{2}\right]$

$d \quad$ Diâmetro da cratera de desgaste [mm]

D Diâmetro da esfera de ensaio [mm] 
$D P_{k} \quad$ Desvio-padrão do coeficiente de desgaste $\left[\mathrm{mm}^{3} / \mathrm{N} . \mathrm{m}\right]$

$C$ Concentração de lama abrasiva [\% $\mathrm{SiC}+\% \mathrm{H}_{2} \mathrm{O}$ destilada - em colume]

$f_{g} \quad$ Frequência de gotejamento da lama abrasiva entre a esfera de ensaio e o corpo-de-prova [gota/s]

$h \quad$ Profundidade da cratera de desgaste $[\mu \mathrm{m}]$

$k \quad$ Coeficiente de desgaste $\left[\mathrm{mm}^{3} / \mathrm{N} . \mathrm{m}\right]$

$k_{c} \quad$ Coeficiente de desgaste do revestimento ("coating") $\left[\mathrm{mm}^{3} / \mathrm{N} . \mathrm{m}\right]$

$k_{s} \quad$ Coeficiente de desgaste do substrato $\left[\mathrm{mm}^{3} / \mathrm{N} . \mathrm{m}\right]$

$k_{t} \quad$ Coeficiente de desgaste total (substrato + revestimento) $\left[\mathrm{mm}^{3} / \mathrm{N} . \mathrm{m}\right]$

$n$ Rotação da esfera de ensaio [rpm]

$N \quad$ Força normal [N]

$R \quad$ Raio da esfera de ensaio [mm]

$R P D$ Regime Permanente de Desgaste

$S \quad$ Distância de deslizamento [m]

$t \quad$ Tempo de ensaio [min ] elou [s]

$v \quad$ Velocidade tangencial da esfera de ensaio $[\mathrm{m} / \mathrm{s}]$

$V \quad$ Volume da cratera de desgaste $\left[\mathrm{mm}^{3}\right]$

$\% A_{g} \quad$ Porcentagem de atuação de desgaste micro-abrasivo por "riscamento" na superfície da cratera de desgaste [\%]

$\% A_{r} \quad$ Porcentagem de atuação de desgaste micro-abrasivo por "rolamento" na superfície da cratera de desgaste [\%] 